\title{
Numerical Modeling of Concrete Spallation at Medium Strain-rate
}

\author{
Ammar Babiker ${ }^{1,2 *}$, Ulrich Häussler-Combe ${ }^{1}$, Aamir Dean ${ }^{3,4}$, Salih E. M. Ahmmed ${ }^{2}$ and Elsadig Mahdi ${ }^{5}$ \\ 1 Institute of Concrete Structures, Technische Universität Dresden, Dresden, Germany \\ 2 Department of Civil Enginering, College of Engineering, Sudan University of Science and Technology, Khartoum, Sudan \\ 3 Institute of Structural Analysis, Leibniz University Hannover, Hannover, Germany \\ 4 Elasticity and Strength of Materials Group, School of Engineering, University of Seville, Seville, Spain \\ 5 Department of Mechanical and Industrial Engineering, College of Engineering, Qatar University, Doha, Qatar \\ * Corresponding author: Ammar Babiker (e-mail: ammar.babiker@tu-dreden.de).
}

Article history: Received 29 May 2020, Received in revised form 4 November 2020, Accepted 11 November 2020

\begin{abstract}
Dynamic tensile strength of brittle materials such as concrete is usually obtained by performing laboratory investigations such as direct tensile, Brazilian splitting, and spall tests. This research presents a study aimed to investigate numerically the dynamic behavior of concrete exposed to tensile loading at medium strain-rate. The dynamic tensile behavior of concrete is investigated using the Modified Split Hopkinson Bar (MSHB) at strain-rate ranges from 33 to $80 \mathrm{~s}^{-1}$. The commercial finite element explicit code LS-DYNA is used to perform the numerical simulations of the MSHB tests. Karagozian \& Case Concrete Model $(\mathrm{K} \& \mathrm{C})$ is adopted to define the mechanical properties of the investigated specimens. The employed $\mathrm{K} \& \mathrm{C}$ material model is verified by using the experimental results obtained in [1]. The validation of the $K \& C$ material model is carried out with the comparison of the computed and experimental pull-back velocities of the specimens free end. The results of the analysis are used to enhance the understanding of strain-rate sensitivity of the concrete tensile strength.
\end{abstract}

Keywords: Concrete, Strain-rate, Spallation, Modified Split-Hopkinson-Bar, Dynamic tensile strength, DIF.

\section{INTRODUCTION}

As regards stability and fracture research, one of the main material properties of quasi-brittle materials, such as rock and concrete, is the dynamic tensile strength. There are several theoretical approaches to, directly and indirectly, calculate the rock's dynamic tensile strength, see [2] for more details. Spalling test using the Modified Split Hopkinson Bar (MSHB) is one of the direct tests to measure the dynamic tensile strength of brittle materials such as concrete, mortar, and rock at medium strain rate [3]. A number of experimental and numerical spall tests on cementitious materials have been conducted
[1], [4]-[11]. Most of these studies used cement mortar only in preparing the specimens; however, the test results are used to characterize the concrete material properties. Some studies considered concrete like-material in which fine and coarse aggregates are used to construct the specimens under investigation [12].

The main apparatus of the SHB spall test includes a sticker bar, an incident bar, and a slender rod specimen, as shown in Fig. 1. The incident compressive stress wave produced by an impactor (striker) hitting the incident bar propagates along the bar. When it reaches the specimen, part of it is transmitted into the specimen, whereas the rest is reflected back to the Hopkinson bar owing to the impedance 
difference. When the transmitted compressive stress wave arrives at the free end of the specimen, it is reflected as tensile stress, which may lead to fracture of the specimen if the maximum tensile stress is equal to the dynamic tensile strength. Fig. 1 shows the propagation of waves during the spall test.
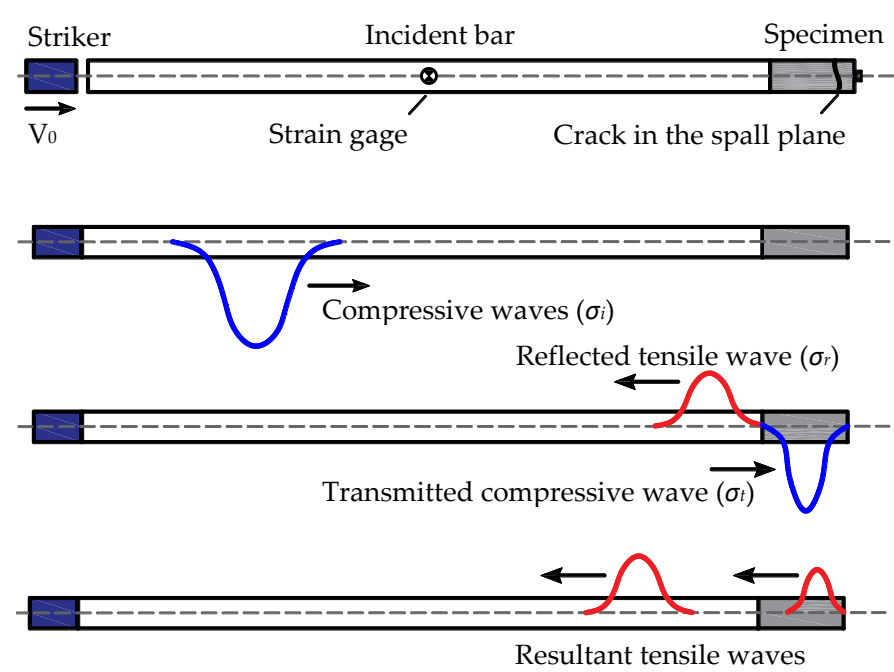

Fig. 1. Wave propagation is spall experiments over time.

\section{TENSILE STRENGTH DEDUCING}

\section{A. Indirect or analytic method}

Several techniques have been proposed to evaluate the spall strength of concrete. A linear acoustic approximation (1) proposed by Novikov

et al. [13] to obtain the spall strength from the velocity recorded on the rear face of the specimen. It has been applied by Schuler et al. [1].

$$
\sigma_{t, d y n}=\frac{1}{2} \rho C \Delta v_{p b}
$$

where $\rho$ is the density of the specimen material, $C$ is the wave propagation velocity, and $\Delta v_{p b}$ denotes the pull-back velocity, is the difference of the velocity between the maximum value and the rebound velocity, see Fig. 3. However, it is assumed that the material still behaves elastically in between the cracking plane that initiates the rebound and the rear face.

\section{B. Direct method}

Strength valuation using Novikov [13] formula assumes uniaxial stress state and liner elasticity until reaching the perfect tensile brittle failure. At the same time, the simulation model considers multiaxial stress states and nonlinear behavior for the material model. Therefore, this method may underestimate the tensile strength of the material; however, it is used by most researchers. Another method is to compute the tensile stress directly from the stress wave history at different locations along the specimen, see Fig. 2.

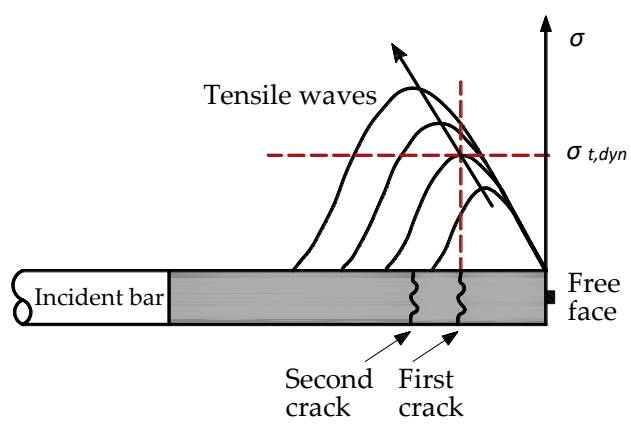

Fig. 2. Schematic for dynamic tensile strength calculation.

The dynamic tensile stress distribution along the specimen can be obtained as a function of time, which can be used to obtain the net tensile stress at any instant along the specimen; therefore, the nominal tensile strength of the concrete can be obtained through the measurement of the location of the first crack, see Fig. 2. This value is considered as the material dynamic tensile strength.

\section{SPECIMEN'S WAVE VELOCITY AND DYNAMIC YOUNG'S MODULUS}

The specimen's wave velocity $C$ and its dynamic Young's modulus $E_{d y n}$ can be estimated, with the time-history signals at the beginning of the specimen and the particle velocity measured at the free surface at the end of the specimen using (2) and (3), respectively.

$$
\begin{aligned}
& C=\frac{L}{\Delta t} \\
& E_{d y n}=\rho C^{2}
\end{aligned}
$$


where $\Delta t$ is the time that the wave needs to propagate from the beginning to the end of the specimen, see Fig. 3, L is the specimen's length.

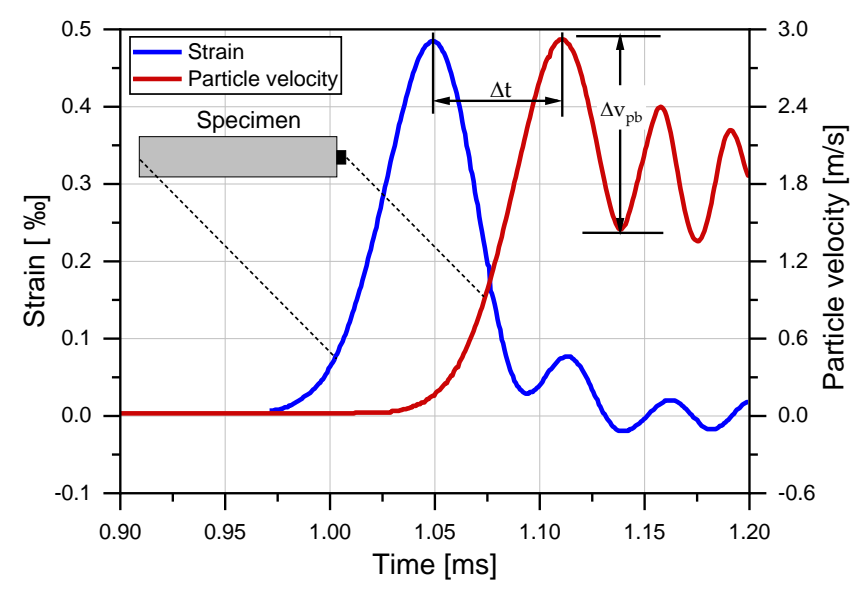

Fig. 3. Typical pull-back in the spall test, adapted from [1].

\section{NUMERICAL MODELING OF SPALLATION TEST}

This Section presents numerical simulations of wave propagation in the modified SHB test. The simulations were performed using LS-DYNA commercial software that is an explicit finite element code suitable to analyze dynamic problems with wave propagation involved. The modeling aspects, including the geometry discretization, element properties, material models, loading rates, boundary conditions, and contact algorithms used herein work, are briefly presented below.

\section{A. Geometry, mesh and elements type}

The finite element model of the complete split Hopkinson pressure bar was developed, including a striker bar, incident bar, and concrete specimen. The dimensions are given with $75 \mathrm{~mm}$ for the diameter of all parts and lengths of $60 \mathrm{~mm}$ for the striker bar, $5500 \mathrm{~mm}$ for the incident bar, and $250 \mathrm{~mm}$ for the concrete specimen with a mesh size of about $6 \mathrm{~mm}$. Fig. 4 . Shows the layout of the model and the mesh discretization used for the finite element analysis.

Eight-node hexahedron solid elements were used to model all parts of the SHB system. The default element formulation (ELFORM=1) was adopted herein work. An overview of the number of elements used for any part is presented in Table 1.
TABLE 1: NUMBER OF ELEMENTS USED IN EACH MODEL

\begin{tabular}{llc}
\hline \hline Part & Element type & Number of elements \\
\hline Concrete & 8-node solid & 3150 \\
Incident bar & 8-node solid & 1050 \\
Striker bar & 8-node solid & 42000 \\
\hline \hline
\end{tabular}

Three different striking velocities were investigated, namely 4.1, 7.6, and $11.1 \mathrm{~m} / \mathrm{s}$. an initial gap of $1 \mathrm{~mm}$ is given between the striker and the incident bar. The velocity was assigned to the sticker bar nodes using the LS-DYNA keyword Initial velocity generation.

A single-surface contact was considered at the interface between the striker and incident bars, while the concrete specimen has its interfacing nodes in common with the incident bar to simulate perfect glue.

\section{CONSTITUTIVE MATERIAL MODEL}

For each phase of the 3D finite element model, ab appropriate material formulation should be defined. In the present study, three material models are used to simulate the concrete matrix, steel striker bar, and aluminum incident bar in an SHB test. The following describes the material models used for each part of the model.

\section{A. Material model for concrete matrix}

LS-DYNA code offers several material models that can be employed to model concrete. In this research, Karagozian \& Case concrete damage model is adopted to assign the mechanical properties of the concrete matrix. The Karagozian and Case concrete model $(\mathrm{K} \& \mathrm{C})$ is an advanced elastic-plastic material model. It is one of the most employed material models for concrete. K\&C material model use three shear failure surfaces include damage and strain-rate effect. It has origins based on Pseudo-Tensor ( ${ }^{*}$ MAT 16). They are both use three yield surfaces that describe the behavior of the material. The modifications that conducted to the original formulation ensured that the material behavior is improved by following the experimental monitoring for the uniaxial, biaxial, and triaxial tests for tension and compression. The three yield surfaces are the initial, the maximum, and the residual yield surface, as illustrated in Fig. 5.

At the initial stage of loading or reloading, the 
Fig. 4. Finite element model of the Hopkinson bar spallation setup.

deviatoric stresses are elastic until the stress point reaches the initial yield surface. After then, the deviatoric stresses can increase up to the maximum yield surface. After this stage, the response becomes perfectly plastic or soften to the residual yield surface [14], [15]. The K\&C failure surfaces are defined by several independent parameters, see (4), (5), and (6).

$$
\begin{aligned}
& \sigma_{y}=a_{0 y}+\frac{p}{a_{1 y}+a_{2 y} p} \text { (Initial yield surface) } \\
& \sigma_{m}=a_{0}+\frac{p}{a_{1}+a_{2} p} \text { (Maximun yield surface) } \\
& \sigma_{r}=\frac{p}{a_{1 f}+a_{2 f} p} \text { (Residual yield surface) }
\end{aligned}
$$

where $p$ is the hydrostatic pressure and $\sigma$ is the yield stress specified by the respective index of each surface. The corresponding input parameters $a_{0 y}, a_{1 y}, a_{2 y}, a_{0}, a_{1}, a_{2}, a_{1 f}$ and $a_{2 f}$ define the shape of the surfaces.

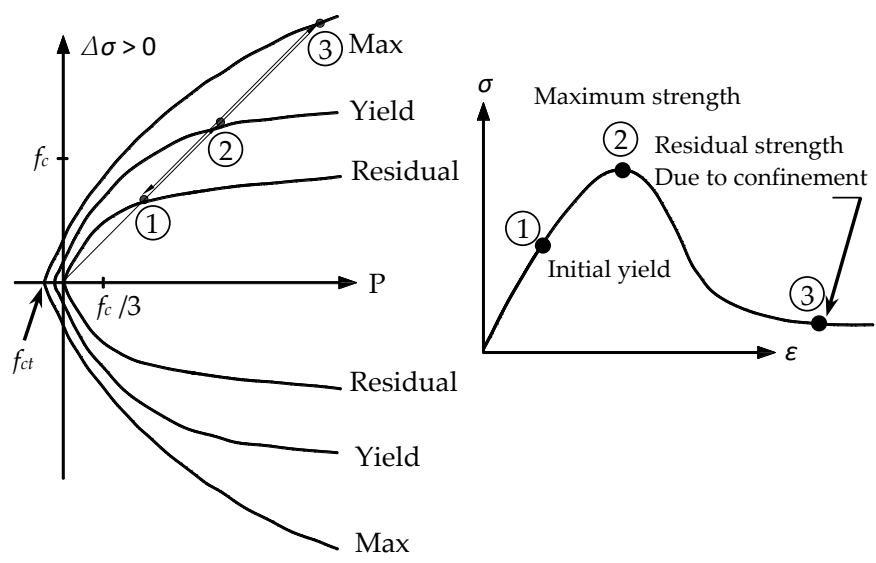

Fig. 5. Pseudo-Tensor model, adapted from Malvar et al. [14]: (a) failure surfaces and, and (b) stress-strain curve.

The most significant improvement offered by the latest $\mathrm{K} \& \mathrm{C}$ formulation is an input automatic generation capability, mainly based on one single user input parameter, which is the unconfined compressive strength of the concrete. More detail on $\mathrm{K} \& \mathrm{C}$ material formulation can be found in [14], [16].

\section{a) Damage function}

In the $\mathrm{K} \& \mathrm{C}$ concrete damage model, the change in stress as a function of plastic strain is governed by the damage functions, which are defined in (7).

$$
\lambda= \begin{cases}\int_{0}^{\bar{\varepsilon}^{p}} \frac{d \bar{\varepsilon}^{p}}{r_{f}\left(1+p / r_{f} f_{t}\right)^{b_{1}}} & \text { when } p \geq 0 \\ \int_{0}^{\bar{\varepsilon}} \frac{d \bar{\varepsilon}^{p}}{r_{f}\left(1+p / r_{f} f_{t}\right)^{b_{2}}} & \text { when } p<0\end{cases}
$$

where $d \bar{\varepsilon}^{p}$ is the effective plastic strain increment, $d \bar{\varepsilon}^{p}=\sqrt{2 / 3 \varepsilon_{i j}^{p} \varepsilon_{i j}^{p}}, b_{1}$ and $b_{2}$ are the damage scaling parameters in compression and tension, respectively, and $r_{f}$ is the dynamic increase factor that accounts for strain-rate effects.

In Fig. 6, the original damage function for the Karagozian \& Case concrete model is illustrated.

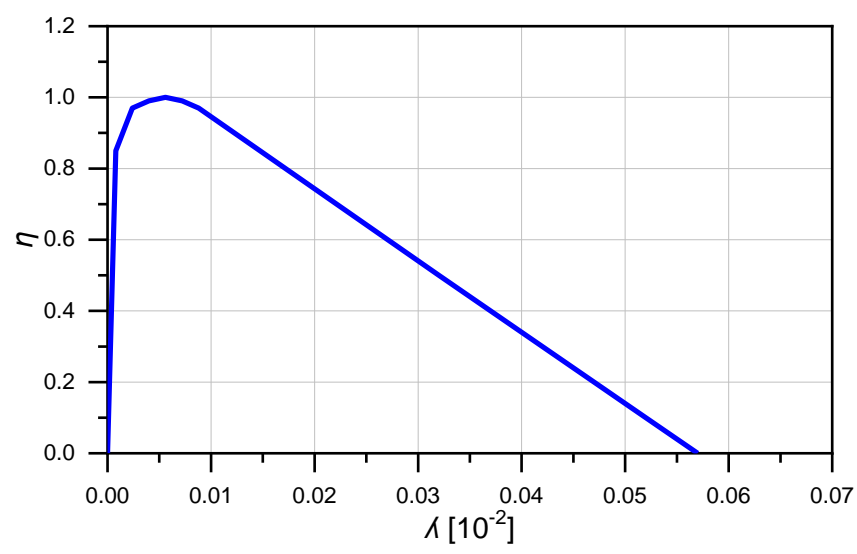

Fig. 6. Damage function for the $\mathrm{K} \& \mathrm{C}$ concrete model.

\section{b) Equation of state}

The volumetric behavior is governed by a compaction curve, also known as the equation of state (EOS). The equation of state describes the compressive behavior of the material. EOS provides the pressure $p$ as a function of the volumetric strain and internal energy. A tabulated compaction model is used with the $\mathrm{K} \& \mathrm{C}$ model, which is a linear in the internal energy. The pressure is given by (8).

$$
p=C\left(\varepsilon_{v}\right)+\gamma \cdot T\left(\varepsilon_{v}\right) E
$$


The function $C\left(\varepsilon_{v}\right)$ is given as a series of $\left(p, \varepsilon_{v}\right)$ pairs. The EOS prescribes a set of pressures, unloading bulk modulus, and volumetric strains. A typical pressure versus volumetric strain curve for $\mathrm{K} \& \mathrm{C}$ concrete model is presented in Fig. 7.

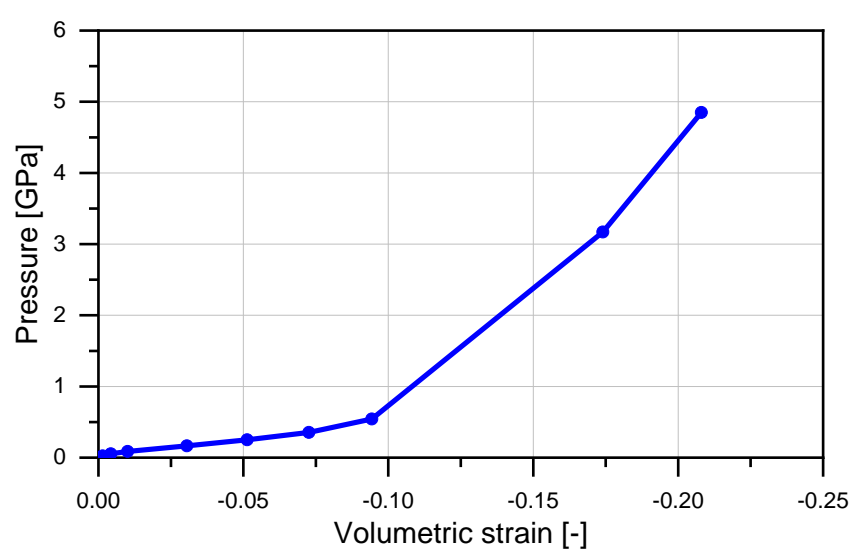

Fig. 7. Pressure versus volumetric strain curve.

c) Strain-rate effect

Concrete is a composite material sensitive to loading rate or strain-rate. In general, concrete shows higher strength when exposed to high strain-rate loading than that under static condition. This increase is always expressed as a dynamic increase factor (DIF), i.e., the ratio of the dynamic to static strength as $\mathrm{s}$ function of strain-rate. An increase in strength in concrete is thought to de due to the inertial resistance of the material as it cracks [17], [18].

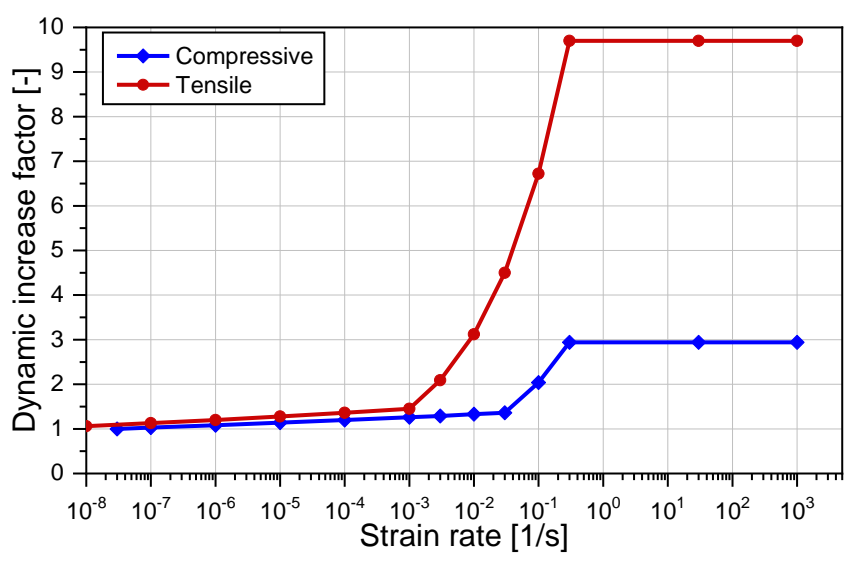

Fig. 8. Strength enhancement curve used with the K\&C model [19].

The formulation recommended by CEB-FIB [20] is one of the most commonly used formulas for deducing the dynamic increase factor of concrete. Malvar and Ross [21] introduced a modified formulation of CEB-FIP model code, which is better to predict strength enhancement in tension, see Fig. 8. The strength enhancement curve in Fig. 8 is operated with the $K \& C$ concrete model to involve strain-rate dependency. The curve is recommended by LS-DYNA user's manual [19].

\section{d) Erosion criterion}

Erosion is a technique used in finite element modeling to remove elements that pass specifically defined criteria. To visualize the damage and spallation process of concrete specimen assigned with the $\mathrm{K} \& \mathrm{C}$ concrete model, many studies have commonly used this approach [22], [23]. By taking advantage of Xu et al. study of split Hopkinson bar, values of 0.15 and 0.8 adopted respectively to define the maximum principal strain and maximum shear strain at failure. The first run was performed without erosion, and the obtained tensile strength shows that erosion has a negligible effect.

\section{B. Material model for striker and incident bars}

The aluminum incident bar, as well as the steel striker bar, are assumed to have liner elastic material ( ${ }^{*}$ MAT 001) in LS-DYNA. The material parameters assigned for each part are summarized in Table 2.

TABLE 2: MATERIAL PARAMETERS USED IN EACH MODEL

\begin{tabular}{llll}
\hline \hline Part & Parameter & Unit & Value \\
\hline Concrete & Unit weight & $\mathrm{Kg} / \mathrm{m}^{3}$ & 2273 \\
${ }^{*}$ MAT072R3) & Compressive strength & $\mathrm{MPa}$ & 50 \\
& $\begin{array}{l}\text { Tensile strength } \\
\text { Modulus of elasticity }\end{array}$ & $\mathrm{MPa}$ & 3.5 \\
& Poisson's ratio & - & 36 \\
& & & 0.2 \\
& Unit weight & $\mathrm{Kg} / \mathrm{m}^{3}$ & 2720 \\
Incident bar & $\mathrm{GPa}$ & 72 \\
${ }^{*}$ MAT 001) & Modulus of elasticity & - & 0.34 \\
& Poisson's ratio & & \\
Striker bar & Unit weight & $\mathrm{Kg} / \mathrm{m}^{3}$ & 7850 \\
${ }^{*}$ MAT001) & Modulus of elasticity & $\mathrm{GPa}$ & 200 \\
& Poisson's ratio & - & 0.3 \\
\hline \hline
\end{tabular}

\section{RESULTS AND DISCUSSIONS}

\section{A. Pull-back velocity}

As the wave signal propagates into the specimen, its particle velocities arise and slow down afterword. The difference in the velocity between the maximum value and the rebound velocity $\Delta v_{p b}$, i.e., the pull-back velocity is very important being used in calculating the dynamic 
tensile strength of the specimen. Fig. 9 shows experimental and numerical obtained velocities of the specimen's free end, depending on time for the impact velocity of $4.1 \mathrm{~m} / \mathrm{s}$. as can be seen, the simulated velocity peak is higher compared to the experimental. In contrast, the pull-back velocities are in good agreement, as can be seen in Table 3.

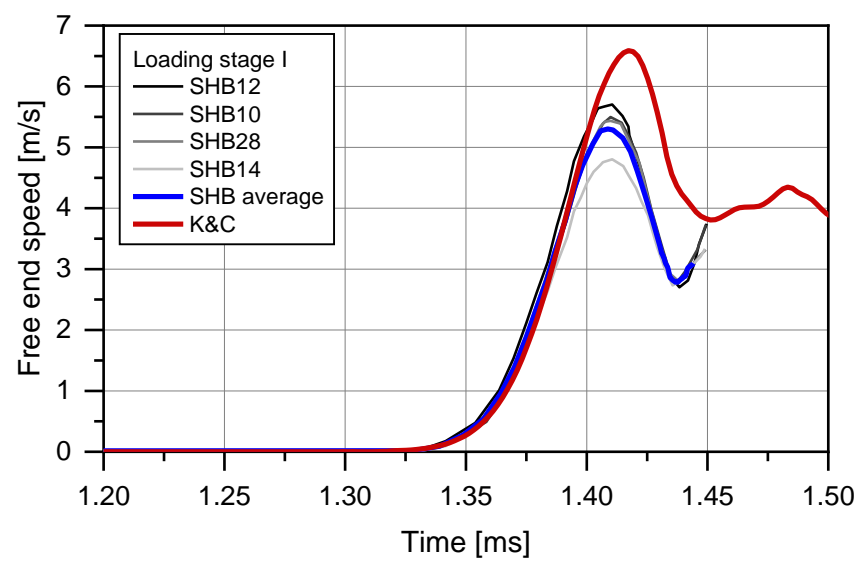

Fig. 9. Velocity profile of right free end for the velocity $4.1 \mathrm{~m} / \mathrm{s}$.
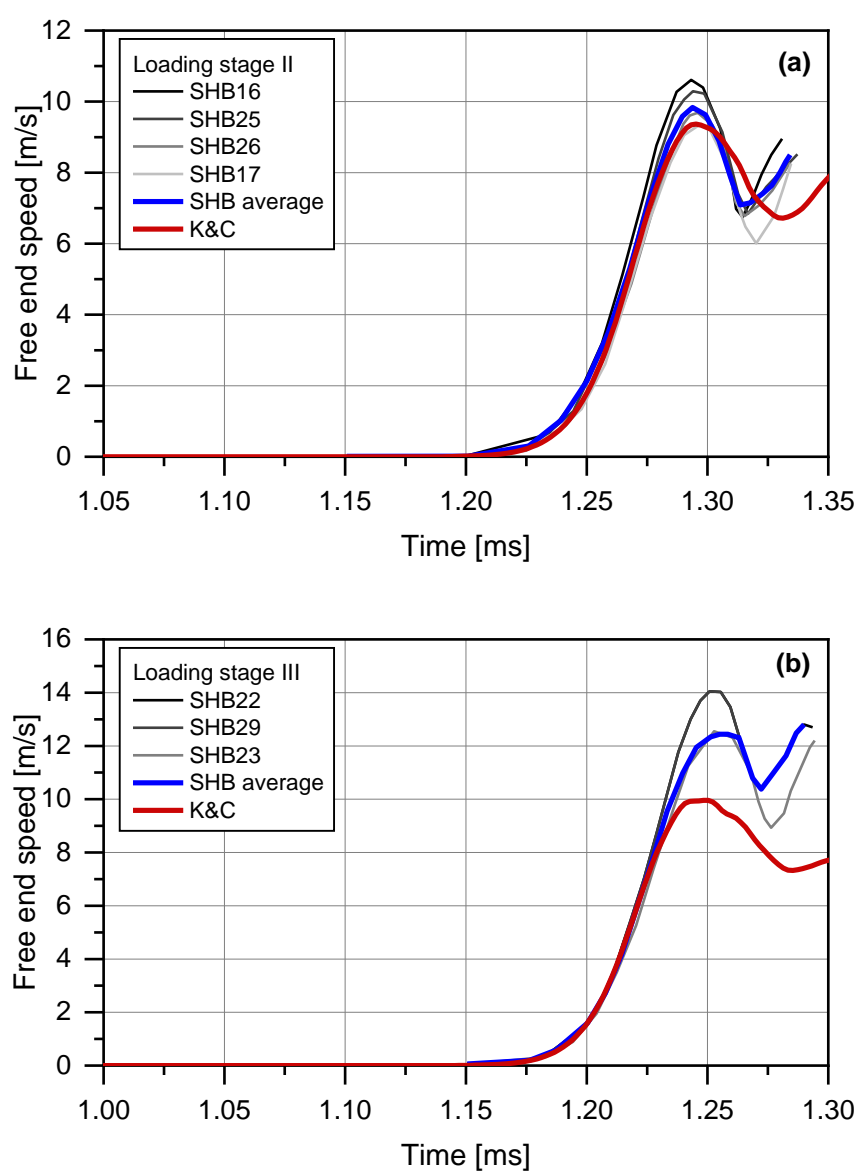

Fig. 10. Velocity profile of right free end of specimens: (a) impact velocity $7.6 \mathrm{~m} / \mathrm{s}$, and (b) impact velocity $11.1 \mathrm{~m} / \mathrm{s}$.

Fig. 14 shows the computed velocities of the specimen free end obtained from the simulations under varying impact velocities along with the experimental ones. This time their peaks are

lower compared to experimental, while their pull-back velocities yield nearly the same. This indicates the accuracy of the FE model as well as the $\mathrm{K} \& \mathrm{C}$ formulation. For more comparison, see Table 3.

TABLE 3: EXPERIMENTAL AND NUMERICAL RESULTS.

\begin{tabular}{llll}
\hline \hline Impact velocity [m/s] & 4.1 & 7.6 & 11.1 \\
\hline $\begin{array}{l}\text { Pull-back velocity [m/s] } \\
\text { Mean of experiments }\end{array}$ & 2.5 & 3.2 & 3.4 \\
$\begin{array}{l}\text { Simulation with K\&C } \\
\text { Dynamic tensile strength [MPa] }\end{array}$ & 2.67 & 3.0 & 3.3 \\
$\begin{array}{l}\text { according to (1) } \\
\text { Mean of experiments }\end{array}$ & $12.9 \pm 1.0$ & $16.2 \pm 2.0$ & $18.0 \pm 0.9$ \\
$\begin{array}{l}\text { Simulation with K\&C } \\
\text { Maximum tensile strength [MPa] } \\
\text { Simulation with K\&C }\end{array}$ & 12.87 & 13.97 & 14.23 \\
$\begin{array}{l}\text { Wave speed C [m/s] } \\
\text { according to (2) }\end{array}$ & 23.00 & 35.87 & 48.77 \\
$\begin{array}{l}\text { Dynamic Young's modulus [MPa] } \\
\text { according to (3) }\end{array}$ & 4156.40 & 4048.10 & 3912.20 \\
$\begin{array}{l}\text { Mean of experiments } \\
\text { Simulation with K\&C }\end{array}$ & $40.1 \pm 1.0$ & $38.7 \pm 1.0$ & $39.9 \pm 0.5$ \\
\hline \hline
\end{tabular}

\section{B. Dynamic tensile strength}

The dynamic tensile strength is measured from the pull-back velocity $\Delta v_{p b}$, as it is explained in Section 2. From the recorded pull-back velocity, Novikov's formula (1) results in $\sigma_{t, d y n}=12.87 \mathrm{MPa}$ from the simulation and $\sigma_{t, d y n}=12.9 \pm 1.0 \mathrm{MPa}$ for the experiments. Fig. 14 illustrates the compressive and tensile stress-time histories of the specimen during the analysis with an impact velocity of $4.1 \mathrm{~m} / \mathrm{s}$.

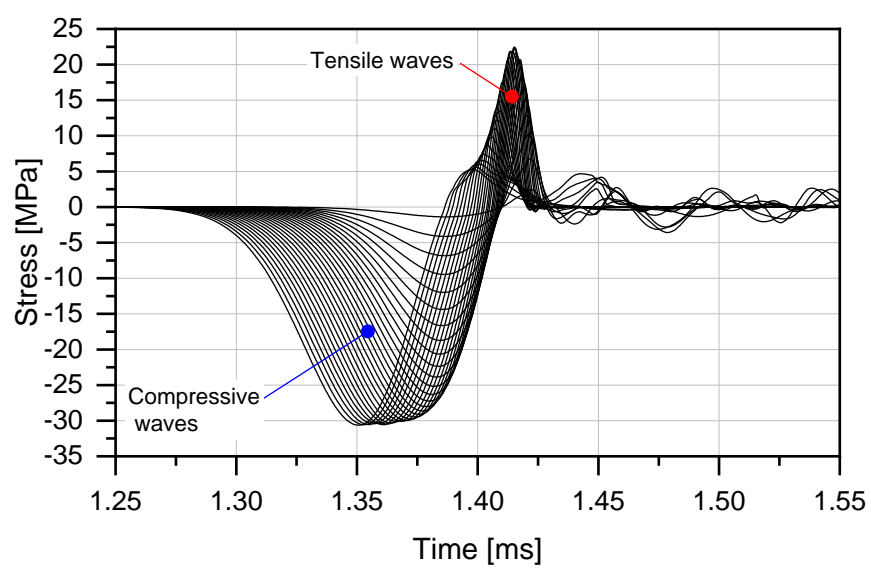

Fig. 11. Longitudinal stress waves in the specimen during the analysis with the impact velocity $4.1 \mathrm{~m} / \mathrm{s}$.

Furthermore, the stress evolution with the highest computed tensile stress is plotted in Fig. 12. 

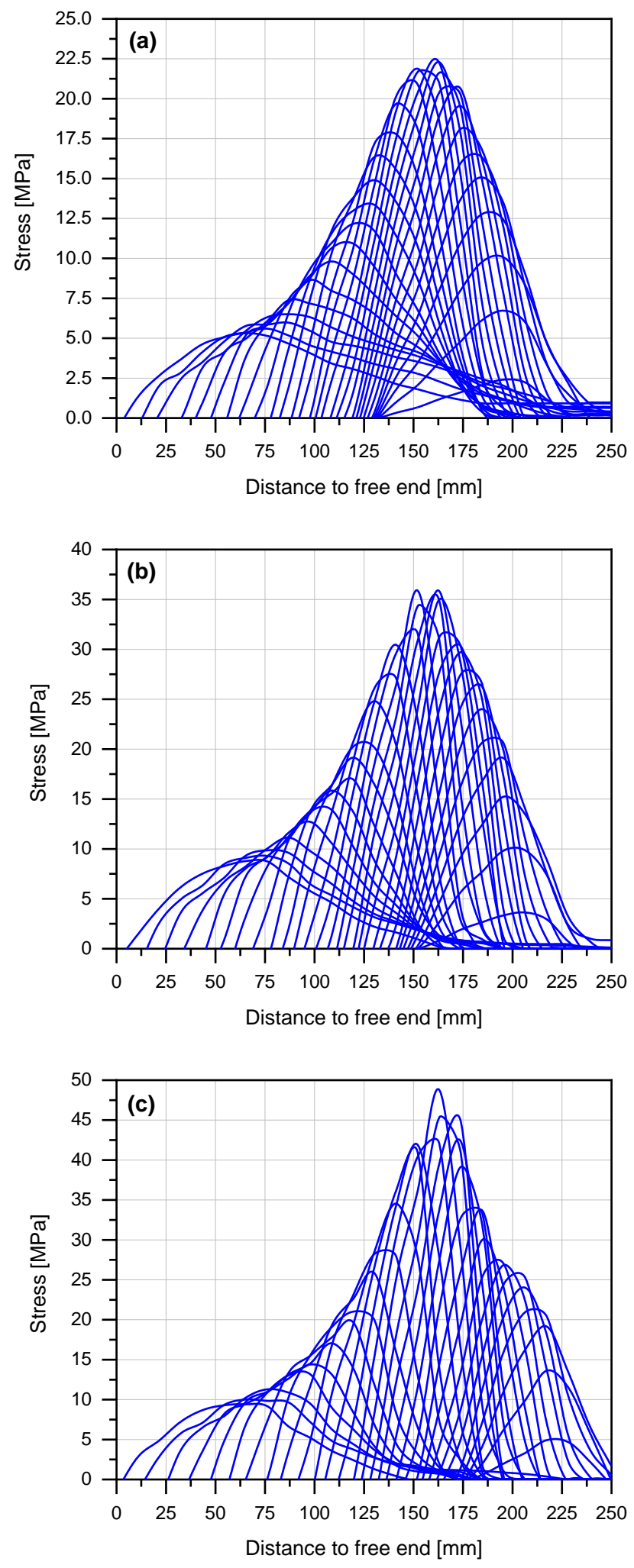

Fig. 12. Stress-time history evolution in the $25 \mathrm{~cm}$ long specimen for the impact velocity: (a) $4.1 \mathrm{~m} / \mathrm{s}$, (b) $7.6 \mathrm{~m} / \mathrm{s}$, and (c) $11.1 \mathrm{~m} / \mathrm{s}$.

The results are measured from the center of the specimen along it is length. The directly computed stresses are in considerable differences comparing to the values calculated using Novikov's formula (1). Therefore, the assumption of linear acoustic approximation, as well as the uniaxial stress states, seems not to be applicable in this particular case. An overview of the dynamic tensile strength obtained from the numerical simulations using both methods the direct and indirect method is given in Table 3 .

\section{Dynamic Young's modulus}

The determination of the dynamic Young's modulus has been discussed in Section 3. As explained, it depends on the elastic wave speed of the specimen's material. The wave speed generally decreases with increasing loading rate, and the wave speed may also vary depends on the material parameters. The measured wave speed and dynamic Young's modulus are given in Table Table 3.

\section{Increase of dynamic tensile strength}

The strain-rate has been calculated from the evolution of the stress in the location of the fracture using (9).

$$
\dot{\varepsilon}=\frac{1}{E}\left(\frac{\partial \sigma_{t}}{\partial t}\right)_{\text {cracklocation }}
$$

where $E$ is the dynamic elastic modulus, $\sigma_{t}$ is the tensile strength at which the fracture occurs and the fracture time is the time interval of the time at which the tensile stress occurs and the time at which the crack takes place.

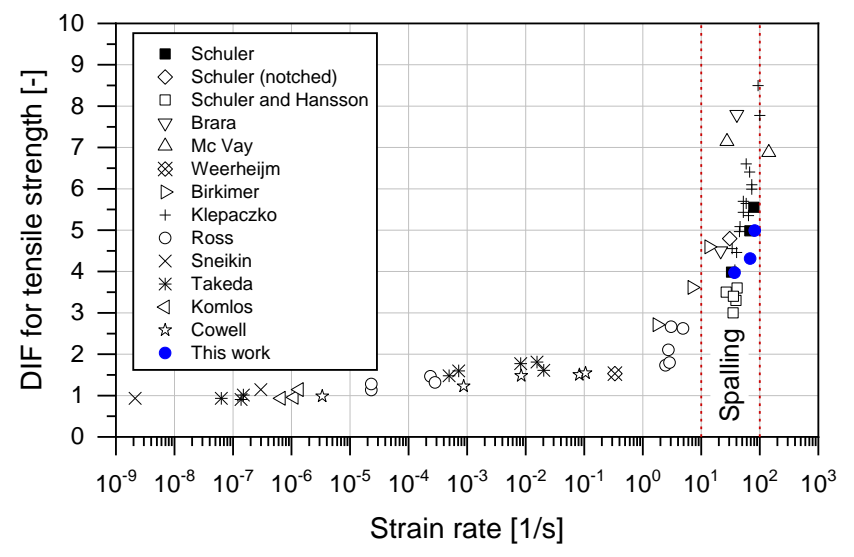

Fig. 13. Dynamic increase factor for tensile strength.

In Fig. 13, the simulations results together with the experimental and other literature data are plotted. At strain rates ranging from 10 to $100 \mathrm{~s}^{-1}$, an increase by a factor DIF $\left(\sigma_{t, d y n} / \sigma_{q s t}\right)=3.97-$ 4.99. The mean value of quasi-static tensile strength was the same as the one used by Schuler 
et al. [1]. As can be seen, the simulated DIF values correspond well with experimental ones.

\section{E. Crack patterns}

Fig. 14 shows the simulation results of the K\&C concrete damage model with the aforementioned experimental set-up Schuler et al. [1] with the sticker impact velocity $4.1 \mathrm{~m} / \mathrm{s}$. As can be seen, the fracture location predicted by the simulation matches well with the experimentally observed crack location.

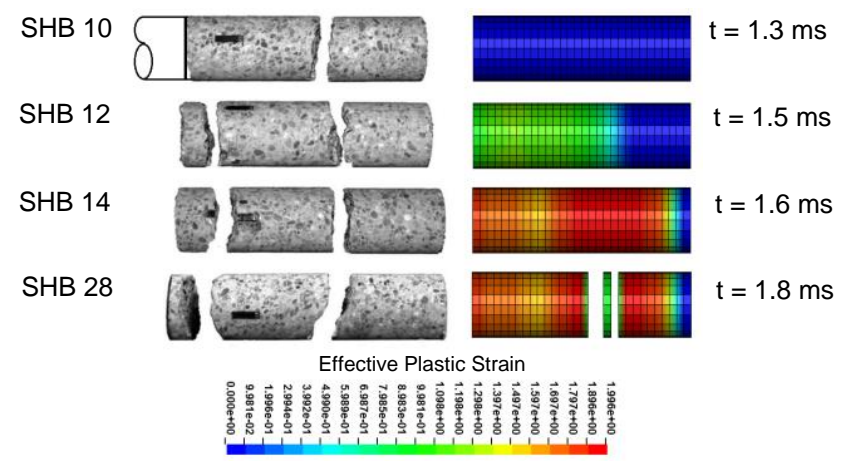

Fig. 14. Comparison of failure patterns with an impact velocity of 4.1 $\mathrm{m} / \mathrm{s}$.

\section{CONCLUSION}

The dynamic behavior and tensile strength of concrete were investigated numerically by employing the 1D wave propagation characteristics. A modified split Hopkinson bar test configuration was simulated and analyzed in terms of pull-back velocity, dynamic tensile strength measurements, dynamic Young's modulus, elastic wave speed, and increase of dynamic tensile strength (DIF). The chosen material model was the Karagozian \& Case concrete damage model ( ${ }^{*} \mathrm{MAT}$ 072R3). Validation of the numerical models was done using the experimental results of Schuler et al. [1]. Two different evaluation methods for deducing the dynamic tensile strength have been discussed. According to the findings, the following remarks may be drawn from this investigation.

Numerical results showed that the linear acoustic approximation proposed by Novikov et al. [13] is valid when applied to the spall experiment, whereas the estimation method based on the pull-back velocity may lead to underestimation of the dynamic tensile strength compared to that using the direct valuation method.

It has been demonstrated that the spalling strength is related to the loading rate, i.e., the impact velocity. The spalling strength has rate sensitivity, which is mainly due to the different micro-cracking paths under different impact velocities (loading rates).

As an overall result, the employed material model in LS-DYNA library can well capture the behavior of concrete exposed to dynamic loading.

\section{ACKNOWLEDGMENT}

The presented work was funded by the Sundanese Ministry of Higher Education and Scientific Research.

\section{REFERENCES}

[1] H. Schuler, C. Mayrhofer, and K. Thoma, "Spall experiments for the measurement of the tensile strength and fracture energy of concrete at high strain rates," Int. J. Impact Eng., vol. 32, no. 10, pp. 1635-1650, 2006.

T. Saksala, "Numerical modelling of dynamic spalling test on rock with an emphasis on the influence of pre-existing cracks," Raken. Mek., vol. 50, no. 2, pp. 63-76, 2017.

[3] H. Kolsky, "An Investigation of the Mechanical Properties of Materials at very High Rates of Loading Related content Anisotropy in Mechanical Relaxations in Uniaxially Oriented Polymers Yasuaki Kawamura and Yasaku Wada-Molecular Motions and Related Mechanical Relaxat," 1949.

[4] J. R. Klepaczko and A. Brara, "Experimental method for dynamic tensile testing of concrete by spalling," Int. J. Impact Eng., vol. 25, no. 4, pp. 387-409, 2001.

[5] A. Brara, F. Camborde, J. R. Klepaczko, and C. Mariotti, "Experimental and numerical study of concrete at high strain rates in tension," Mech. Mater., vol. 33, no. 1, pp. 33-45, 2001.

[6] A. Brara and J. R. Klepaczko, "Experimental characterization of concrete in dynamic tension," Mech. Mater., vol. 38, no. 3, pp. 253-267, 2006.

[7] J. Weerheijm and J. C. A. M. Van Doormaal, "Tensile failure of concrete at high loading rates: New test data on strength and fracture energy from instrumented spalling tests," Int J. Impact Eng., vol. 34, no. 3, pp. 609-626, 2007.

[8] H. Wu, Q. Zhang, F. Huang, and Q. Jin, "Experimental and numerical investigation on the dynamic tensile strength of concrete," Int. J. Impact Eng., vol. 32, no. 1-4, pp. 605-617, 2005.

[9] B. Erzar and P. Forquin, "An experimental method to determine the tensile strength of concrete at high rates of strain," Proc. Soc. Exp. Mech. Inc., vol. 67, pp. 941-955, 2010.

[10] F. G. Díaz-Rubio, J. R. Pérez, and V. S. Gálvez, "The spalling of long bars as a reliable method of measuring the dynamic tensile strength of ceramics," Int. J. Impact Eng., vol. 27, pp. 161-177, 2002.

[11] L. Zhang, S. S. Hu, D. X. Chen, Z. Q. Yu, and F. Liu, "An experimental technique for spalling of concrete," Exp. Mech., vol. 49, no. 4, pp. 523-532, 2009.

[12] B. Erzar and P. Forquin, "Analysis and modelling of the cohesion strength of concrete at high strain-rates," Int. J. 
Solids Struct., vol. 51, no. 14, pp. 2559-2574, 2014.

[13] Novikov SA, Divnov II, and Ivanov AG, "The study of fracture of steel, aluminium and copper under explosive loading," Fiz. Met. i Metalloved., vol. 21, no. 4, 1966.

[14] L. J. Malvar, J. E. Crawford, J. W. Wesevich, and D. Simons, "A plasticity concrete material model for DYNA3D," Int. J. Impact Eng., vol. 19, no. 9-10, pp. 847-873, 2002.

[15] N. Markovich, E. Kochavi, and G. Ben-Dor, "Calibration of a Concrete Damage Material Model in LS-Dyna for a Wide Range of Concrete Strengths," IWSRIB_2009_Haifa, 2009.

[16] K. U. S. Manual and V. Ii, LS-DYNA Keyword User' S Manual Volume II Material Models, vol. II, no. February. 2018.

[17] P. H. Bischoff and S. H. Perry, "Compressive behaviour of concrete at high strain rates," Mater. Struct., vol. 24, no. 6, pp. 425-450, 1991.

[18] Z. S. Tabatabaei, J. S. Volz, J. Baird, B. P. Gliha, and D. I. Keener, "Experimental and numerical analyses of long carbon fiber reinforced concrete panels exposed to blast loading," Int. J. Impact Eng., vol. 57, pp. 70-80, 2013.

[19] LSTC, LS-DYNA Keyword Users's Manual II - R8.0, vol. II. 2002.

[20] T. Telford, “CEB-FIP 1990 .pdf.” Lausanne, Switzerland, 1991.

[21] L. J. Malvar and C. A. Ross, "Review of Strain Rate Effects for Concrete in Tension," ACI Mater. J., vol. 95, no. 6, pp. 735-739, Nov. 1998.

[22] X. Q. Zhou and H. Hao, "Modelling of compressive behaviour of concrete-like materials at high strain rate," Int. J. Solids Struct., vol. 45, no. 17, pp. 4648-4661, 2008.

[23] K. Xu and Y. Lu, "Numerical simulation study of spallation in reinforced concrete plates subjected to blast loading," vol. 84, pp. 431-438, 2006.
Ammar Babiker received a B.Sc. in civil engineering from Sudan University of Science and Technology, Sudan in 2010, and an M.Sc. in Advanced Computational and Civil Engineering Structural Studies from TU Dresden, Germany in 2017. Currently, he is a Ph.D. candidate at the Institute of Concrete Structures of the TU Dresden. Since 2017, he has been appointed as a lecturer at Sudan University of Science and Technology. Ammar is now associated as a researcher at the Institute of Concrete Structure of the TU Dresden. His main research interests are fiber-reinforced cement-based composites, material modeling, impact analysis, and strain-rate effect in concrete and cement-based composites.

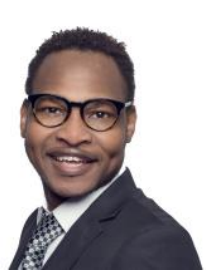

Aamir Dean is a visiting professor at the Elasticity and Strength of Materials Group University of Seville, Spain. Before that, he was leading the research group 'Fatigue' at the Institute of Structural Analysis, Leibniz University Hannover, Germany. $\mathrm{He}$ received two doctorate degrees, in Mechanical Engineering and Industrial Management in 2020 from the University of Seville, Spain, and also in Civil Engineering from the Leibniz University Hannover, Germany in 2017. He is active in the field of computational-, multi-physics-, inelastic-modeling of heterogeneous and anisotropic materials, with a particular interest in polymer composites. In recognition of his research achievements, he has been awarded the Hannover Award of Science, Germany, and the Chamber of Engineers Prize, Germany 